To be presented at Microscopy \& Microanalysis 98

Atlanta, Georgia, July 12-16, 1998, and published in Proceedings

\title{
Z-Contrast Scanning Transmission Electron Microscopy of Nanometer-Scale Coated Particulate Materials*
}

H. J. Gao, ${ }^{1,2}$ Y. Yan, ${ }^{1}$ J. Fitz-Gerald, ${ }^{2}$ D. Kumar, ${ }^{2}$

R. K. Singh, ${ }^{2}$ and S. J. Pennycook ${ }^{1}$

${ }^{1}$ Solid State Division, Oak Ridge National Laboratory

P.O. Box 2008, Oak Ridge, Tennessee 37831-6030

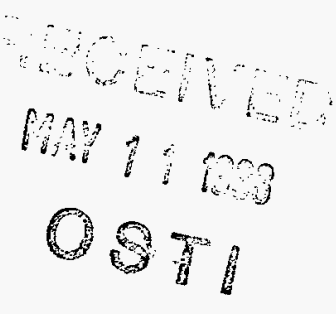

2Department of Materials Science and Engineering

University of Florida, Gainesville, Florida 32611

\footnotetext{
*This research was sponsored by the Division of Material Science, U. S. Department of Energy under contract No. DE-AC05-96OR22464 with Lockheed Martin Energy Research Corp.
}

DISTRIBUTION OF THIS DOCUMENT IS UNLIMITED

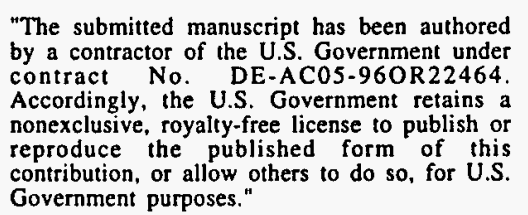

"The submitted manuscript has been authored by a contractor of the US. Government under No. DE-AC05-960R22464. Accordingly, the U.S. Government retains a reproduce the published form of this Government purposes."

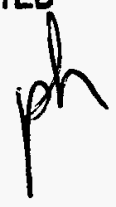

\section{MASTER}

\author{
prepared by \\ SOLID STATE DIVISION \\ OAK RIDGE NATIONAL LABORATORY \\ Managed by \\ LOCKHEED MARTIN ENERGY RESEARCH CORP. \\ under \\ Contract No. DE-AC05-96OR22464 \\ with the \\ U.S. DEPARTMENT OF ENERGY \\ Oak Ridge, Tennessee
}

February 1998

[DTIS QURLI: A:E WOTED 


\section{DISCLAIMER}

This report was prepared as an account of work sponsored by an agency of the United States Government. Neither the United States Government nor any agency thereof, nor any of their employees, makes any warranty, express or implied, or assumes any legal liability or responsibility for the accuracy, completeness, or usefulness of any information, apparatus, product, or process disclosed, or represents that its use would not infringe privately owned rights. Reference herein to any specific commercial product, process, or service by trade name, trademark, manufacturer, or otherwise does not necessarily constitute or imply its endorsement, recommendation, or favoring by the United States Government or any agency thereof. The views and opinions of authors expressed herein do not necessarily state or reflect those of the United States Government or any agency thereof. 


\title{
For MSA meet ing ( 98 Aflanta)
}

\section{Z-CONTRAST SCANNING TRANSMISSION ELECTRON MICROSCOPY OF NANOMETER-SCALE COATED PARTICULATE MATERIALS}

\author{
H.J. Gao, ${ }^{1,2}$ Y. Yan, ${ }^{2}$ J. Fitz-Gerald, 'D. Kumar, 'R.K. Singh, ' S.J. Pennycook ${ }^{2}$ \\ ${ }^{1}$ Department of Material Sciences and Engineering, University of Florida, Gainseville, \\ FL 32611 \\ ${ }^{2}$ Solid Sate Division, Oak Ridge National Laboratory, Oak Ridge, TN 37831
}

Particulate materials with unique functional properties have been the focus of much attention in recent years. Of particular interest, due to their considerable scientific and technological importance, are particles coated with nanoparticles. These have greatly stimulated interest for their novel structure and properties. In these kinds of particulate materials, the interface structures between the support particle and the nanoparticle play a crucial role in controlling their properties. Consequently, imaging of the atomic structures at the interfaces can provide deep understanding of the relationship between the particulate and the corresponding properties. Z-contrast scanning transmission electron microscope (STEM) provides a new view of materials on the atomic scale, a direct image of atomic structure composition which can be interpreted without the need for any preconceived model structure. Therefore it is a powerful tool in the study of particulate materials. In this report, we will present the structures of 18 micron diameter alumina particles coated with Ag nanoparticles.

Particulates were prepared by a laser ablation technique, which involves laser ablation of the target material $(\mathrm{Ag})$ onto a fluidized bed of core particles (alumina). The core alumina particles were fluidized inside the deposition system using a mechanical vibration method. For the STEM analysis, the particulates were lightly crushed in water using a pestle and mortar, then diluted in ethanol and deposited on a TEM grid coated with an amorphous carbon thin film.

Fig. 1 presents bright field and dark field images of the crushed nano-Ag coated alumina. From the dark field image, one can clearly see the small bright Ag particles attached to the substrate alumina. To further investigate the behavior of the interfaces between the nanoparticles and the alumina, as well as their atomic structures, we tilted the sample and observed the interesting area where the $\mathrm{Ag}$ nanoparticle just connects with the substrate. In Fig. 2, the low magnification (A), and high magnification (B) dark field images, and the high magnification bright field image $(C)$, clearly show the interface with a distinct facet structure, which implies that there is no significant intermixing. Fig. 3(A) presents the multiply twinned structure of another laser ablation deposited Ag nanoparticle on alumina. Fig. 3 (B) and (C) gives the atomic structure of the Ag nanoparticle. From the image (C) the distances of $A B, B C$, and $B D$ are $0.30 \mathrm{~nm}, 0.43 \mathrm{~nm}$, and $0.26 \mathrm{~nm}$, respectively, which are consistent with crystalline $\mathrm{Ag}$ in the $\langle 110\rangle$ projection. It is clear that the $\mathrm{Ag}$ atomic structure is maintained right to the surface of the nanoparticle, i.e., that there is no significant layer of Ag-oxide on the surface of the particle. Our experimental results indicate that the STEM can be a powerful tool in the characterization of engineered particulates.

\section{References}

1. R.K. Singh, \& J. Narayan, Phys. Rev., B 43, (1990)8843.

2. R.K. Singh, \& J. Fitz-Gerald, J. Mater. Res. 1998 (to be published).

3. S.J. Pennycook, Ann. Rev. Mater. Sci., 22, (1992)171.

4. N.D. Browning, M.F. Chisholm, and S.J. Pennycook, Nature, 366, (1993)143. 

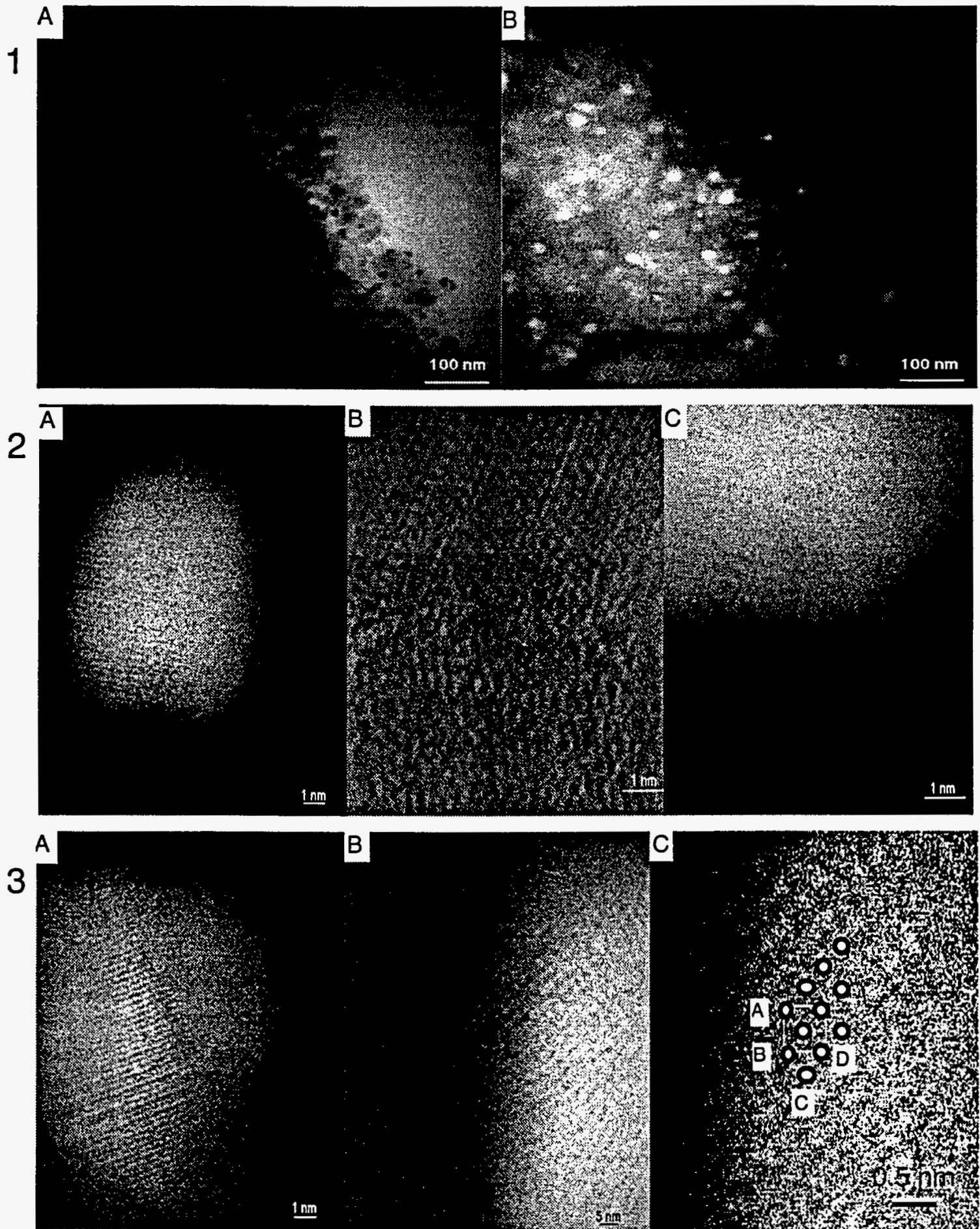

$\underline{1 \mathrm{~nm}}$

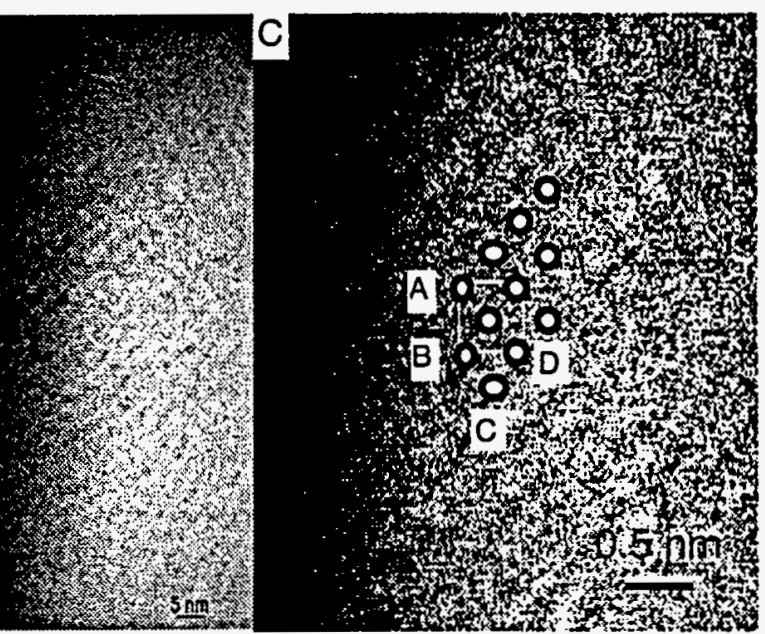

FIG. 1 Low magnification bright field (A) and dark field (B) images of Ag nanoparticles on an 18 micron alumina support particle.

FIG. 2 Images of a faceted Ag nanoparticle on alumina support particle.

FIG. 3 (A) Multiply twinned particle. (B) and (C) Atomic resolution dark field images showing Ag lattice structure at the particle surface. 


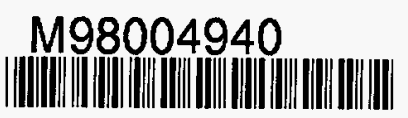

Report Number (14) ORNL/CP--96743

CONF-980713--

Publ. Date (11) DoE $\frac{199802}{\text { Sponsor Code (18) XR XF }}$

UC Category (19) UC-4OA,DOE/ER 